\title{
Introducing complementary foods in the first year of life
}

\author{
Francesco Tandoi, Laura Morlacchi, Angela Bossi, Massimo Agosti \\ S.C. Neonatologia, Terapia Intensiva Neonatale e Pediatria Verbano, ASST dei Sette Laghi - Polo universitario, \\ Ospedale “F. Del Ponte", Varese, Italy
}

\begin{abstract}
Introduction of solid foods is a fundamental step in the development of an individual. There are many implications that weaning contains not only on a nutritional plan, but also on the contingent and long-term health of an individual.

Over time this nutritional passage has evolved through the acquisition of new knowledge about maturation of anatomical and neurosensory structures involved in all the phases of such a complex process.

The understanding of a maturing taste of infant and cultural changes is another key to understand the evolution of introduction of solid foods in infants.

What is contained in this text encapsulates thus the evolutionary path of weaning in recent years, showing current trends in the light of cultural changes and new scientific acquisitions.
\end{abstract}

\section{Introduction}

Introduction of solid food is to be considered as a very important step in nutritional history of each individual. Paediatrician's task is to evaluate the best timing and ways of introducing foods,

Correspondence: Massimo Agosti, S.C. Neonatologia, Terapia Intensiva Neonatale e Pediatria Verbano, ASST dei Sette Laghi, Polo universitario, Ospedale "Filippo Del Ponte" - via Filippo Del Ponte 19, 21100 Varese, Italy.

Tel.: +39.0332.299421 - Fax: +39.0332.299422.

E-mail: massimo.agosti@asst.settelaghi.it

Key words: Complementary food; newborn; weaning.

Contributions: the authors contributed equally.

Conflict of interests: the authors declare no potential conflict of interest.

Funding: Funded by Merqurio Editore S.r.l., with the unconditional contribution of Nestlè Italiana S.p.A.

Received for publication: 6 November 2017.

Accepted for publication: 19 December 2017.

This work is licensed under a Creative Commons Attribution NonCommercial 4.0 License (CC BY-NC 4.0).

(C) Copyright F. Tandoi et al., 2017

Licensee PAGEPress, Italy

La Pediatria Medica e Chirurgica 2017; 39:186

doi:10.4081/pmc.2017.186 taking into account the knowledge of baby's needs matured during the first months of life.

After six months of life, breast milk or formula milk are not nutritionally adequate to meet infant needs, so other nutrients are needed. This happens through a change in the diet regime. The proposal to introduce other foods and/or beverage is therefore defined as complementary nutrition, a term derived from the concept of completing the nutrients provided by breast milk.

Primary purpose of weaning is therefore to increase both the caloric density and the variety of nutrients, favouring the addition of high biological protein and essential fatty acids as well as micronutrients (such as zinc and iron) considered essential to a body in rapid growth as during infancy. ${ }^{1}$

Weaning generally is introduced at the $4^{\text {th }}-6^{\text {th }}$ month of life and progresses gradually throughout the first year.

\section{The biological bases of weaning}

Transition to solid foods must surely satisfy scientific criteria based on validation of a particular food rather than a particular nutritional regime.

From a nutritional point of view, the need to introduce complementary foods lies in the increased need for iron, whose demands grow with growth. ${ }^{2}$

Iron is indispensable for haemoglobin synthesis; this element is not so represented in the composition of breast milk even if well absorbed.

In the early months child uses the reserves of iron stored during intrauterine life, but over time they tend to reduce. Breast milk contains 1 milligram of iron per litre; infant uses it for catabolic reactions, but for its metabolism demands exceed these losses. It is estimated that to increase body weight of one kilogram it is necessary to increase the volume of circulating blood by about 100 $\mathrm{ml}$, equal to about 12 grams of haemoglobin and 36 milligrams of iron. It is clear how the iron intake through breast milk fails to meet these demands. ${ }^{3}$

With regard to the timing of introduction of weaning in the past we have witnessed the tendency to wean the baby early (3th-4th month of life) in relation to neurological development, suggesting small amounts of homogenised foods (predominantly fruit). ${ }^{4}$ Over the years, the evidence revisited this approach, demonstrating that the shift to non-milk foods is indicated for about six months of life in accordance with scientific acquisitions, after comparisons with non-Western cultures, and studies on gastrointestinal maturity. 5,6

At present, within a recent view of an individual's nutritional pathway, the tendency to wean has shifted to a sort of self-regulation about the progression of foods, based on the development of infant's motor skills. This hypothesis enters into the continuum represented by the child's psychophysical development (the abili- 
ty from 5-6 months to indicate desire for food by opening his mouth or moving his head in its direction, the loss in the same period of reflection of tongue protrusions, etc.) and the concept of Natura non facit saltus. ${ }^{7}$ According to these two models even the role of maternal milk remains central, still representing a good source of nutrients beyond the two years of life (as recommended by the World Health Organization), especially to meet the still high calcium requirements in these growth phases. ${ }^{8}$

\section{Weaning practices}

In an enlarged, intercultural scenario, such as the one in which we live today, we must also take a look at weaning in a broader perspective, meaning that every culture faces this passage with the products at its disposal: couscous in Maghreb, oats in Ireland, rice in China, and examples could go on for almost every nation on our planet. 9,10 In industrialized areas, the orientation to this nutritional moment is predominantly characterized by a medicalization in some cases also relevant, often regulated by rigid food schemes and tables. Sometimes its management is not easy. Not so often, weaning has proved to be a difficult path for parents and burdened with fears. ${ }^{10,11}$

In light of what has just been said, we have now wondered whether it is fair to speak of weaning as a standardizable concept, at least in the form in which we have understood it so far, or whether it is necessary to update those principles that have always regulated it. Actually, with the changing of customs, this idea is bound to evolve. For this reason, when solid food is introduced, we need to consider new perspectives and keep in mind concepts that simply did not exist in the past or were considered marginal.

Today, the family culture and child's individuality are the fulcrum of an approach to the introduction of complementary food;10,12 paediatricians and parents (rather than grandparents or nurses) are the figures called to interpret and regulate this phase.

Certainly one point to point out is that weaning is a period of passage during which breast and solid foods coexist. The effect of this coexistence puts in place a dual process: on the one hand the separation of mother and child, on the other, the insertion of the child into the family and social community and the consequent beginning of the discovery of the world, mediated by the use of mechanical tools, spoon, and contact with the breast-fed mother. ${ }^{13}$

The beginning of weaning is certainly a moment to pay attention. Surely when the baby has reached a proper neurological development, it accepts or seeks the novelty. Forcing him to accept something he or she is not ready for, often has the opposite effect. Not so often the conflicts that arise in front of the dish are difficult to solve, sad to live and to see, often exacerbated by unnecessarily rigid attitudes. ${ }^{12,13}$

More consensus has received the choice of the meal to start weaning: in this regard, the introduction of the first meal at noon is linked to a moment of the day most suitable to be lived with patience and serenity. The last meal to be introduced is certainly that of the evening, both for the proximity of the night and for fatigue, which coincides with the child's irritability and nervousness of the mother. Often the evening/night breastfeeding lasts for a long time, sometimes far beyond the introduction of solid food. It is a comforting and relaxing meal that prepares the infant to face the night; for this reason it is more difficult to abolish. ${ }^{14,15}$

Of course, what is to be introduced must take into account various factors such as culture, seasonality, preference for a sweet or salty taste, aspect, which at present is considered being very relevant. Sweet can be a fruit-based meal, salted instead a pumpkin or carrotbased meal, vegetables that are usually used in the early days. ${ }^{16}$
A gluten-free grain flour (of millet, rice, corn) or of other plants, such as tapioca, quinoa, amaranth, buckwheat, is melted with fruit and vegetables puree. ${ }^{17}$

Vegetable broth is for many cultures a starting point to prepare a meal. Though it can be prepared with almost all vegetables (except those belonging to the cabbage and onions family, for known effects on the gut); it is usually preferred to use slightly more sugary vegetables such as pumpkins, carrots or potatoes. ${ }^{18}$

Among dairy products one of the best tolerated is yogurt, which, although made with cow's milk, is fermented, in a certain sense, predigested. Regarding the use of vegetable milks (almond, soy, oats) there is still no unanimous consensus. These can in fact be considered as beverages and, although enriched with calcium, nucleotides, etc, they do not seem to be able to replace breast milk or formula milk at this time. ${ }^{18,19}$

Useful as a protein source are legumes (which can be introduced from 4 months), in particular red or dried lentils or fresh or dried peas, beans and chickpeas carefully reduced in puree. ${ }^{19}$

The nutritional value of extra-virgin olive oil (EVO oil) is not discussed. Added raw to the meal, extra virgin olive oil contains the ideal amount of fat, in a good percentage of monounsaturated (over $70 \%$ ), a low percentage of saturated fat and an even smaller percentage of polyunsaturated. ${ }^{20}$ The presence of the latter, in particular, has its nutritional value: a fair percentage of polyunsaturated fats is indispensable to produce substances such as hormones and for the development of the central nervous system, including retina. Extra-virgin oil also contains antioxidant substances, in particular tocopherols (vitamin E) and polyphenols that counteract oxidation processes. They act by blocking the formation of free radicals, responsible for cell aging and thus preventing oxidation. Thanks to its antioxidants, EVO oil keeps all its nutritional and protective properties intact. 21,22

Even cheese, if added to the meal in the right quantities, may be used from the beginning of weaning. It is a source of high-value amino acids and proteins. Its mineral content (calcium and phosphorus) is essential for mineralization of bones and teeth as well as vitamin B12 (cyanocobalamin) as a cofactor of many metabolic reactions. Although its use is periodically questioned, considering the salt intake, seasoned cheeses, such Parmesan remains, especially in Italy, a habit since the beginning of weaning. ${ }^{22}$

As they contain proteins in their most digestible form, these cheeses still represent a valid protein source well tolerated even in the earliest stages of weaning. This is due to the maturing process that this kind of cheese is subjected to, so that the proteins are predigested and therefore easier to assimilate. 23

The doubt about the appropriateness of preparing home foods has been theoretically finally dissolved. Some studies comparing home and commercial foods administered early (3 to 6 months) demonstrate that at 12 months there is no difference in growth and body composition. ${ }^{24}$

Introduction of new tastes must be constant during weaning. Children should be brought to new flavors gradually. Finding a taste is a nice source of security. Acceptance of typical family foods often represents a winning strategy: recognition by the child, of flavors and aromas known to him during pregnancy, due to their presence in amniotic fluid and breast milk, can facilitate their introduction. 25

\section{Vegetarian/Vegan introduction of complementary food}

There is another way for weaning that does not involve the use of meat (vegetarian) or and, in general, animal proteins (vegan). We 
are talking about vegetarian/vegan weaning that often finds its roots in an ethical choice of the child's parents. The child's health or his/her development and growth can be not affected only if this kind of weaning is done correctly without leaving anything to the case, with the supervision of a paediatrician. In this manner vegan/vegetarian food regime can be safely continued over the time.

A lifestyle based on these principles is a potential preventative tool for overweight and obesity, chronic-degenerative diseases such as hypercholesterolemia, diabetes, intestinal, cardiovascular disease and even tumours. ${ }^{12,26}$

\section{Conclusions}

Weaning is mostly completed in the first year of life, the period within children eat almost everything. The progression of dentition, variable from infant to infant, and the development of taste are conditioning factors and select the most preferred foods. The moment to suspend breast-feeding should remain quite free depending on each mother. Weaning should therefore continue as freely to facilitate nutritional fate and the child's somatic and behavioural development. ${ }^{27}$

\section{References}

1. Agostoni C, Decsi T, Fewtrell M, et al. Complementary feeding: a commentary by the ESPGHAN Committee on Nutrition. J Pediatr Gastroenterol Nutr 2008;46:99-110.

2. Gould JF. Complementary feeding, micronutrients and developmental outcomes of children. Nestle Nutr Inst Workshop Ser 2017;87:13-28.

3. Petry N, Olofin I, Boy E, et al. The effect of low dose ron and zinc intake on child micronutrient status and development during the first 1000 days of life: a systematic review and metaanalysis. Nutrients 2016;8:12.

4. West C. Introduction of complementary foods to infants. Ann Nutr Metab 2017;70 Suppl 2:47-54.

5. Beck AL, Hoeft KS, Takayama JI, Barker JC. Beliefs and practices regarding solid food introduction among Latino parents in Northern California. Appetite 2017;120:381-7.

6. Taylor RW, Williams SM, Fangupo LJ, et al. Effect of a babyled approach to complementary feeding on infant growth and overweight: a randomized clinical trial. JAMA Pediatr 2017;171:838-46.

7. Brown A, Jones SW, Rowan H. Baby-led weaning: the evidence to date. Curr Nutr Rep 2017;6:148-56.

8. Carletti C, Pani P, Monasta L, et al. Introduction of complementary foods in a cohort of infants in Northeast Italy: Do parents comply with WHO recommendations? Nutrients 2017;9:1.

9. Stearns JC, Zulyniak MA, de Souza RJ, et al. Ethnic and dietrelated differences in the healthy infant microbiome. Genome Med 2017 29;9:32.

10. Issanchou S. Habeat consortium. Determining factors and critical periods in the formation of eating habits: results from the Habeat Project. Ann Nutr Metab 2017;70:251-6.
11. Maslin K, Venter C. Nutritional aspects of commercially prepared infant foods in developed countries: a narrative review. Nutr Res Rev 2017;30:138-48.

12. Fewtrell M, Bronsky J, Campoy C, et al. Complementary Feeding: A Position Paper by the European Society for Paediatric Gastroenterology, Hepatology, and Nutrition (ESPGHAN) Committee on Nutrition. J Pediatr Gastroenterol Nutr 2017;64:119-32.

13. Klingberg S, Ludvigsson J, Brekke HK. Introduction of complementary foods in Sweden and impact of maternal education on feeding practices. Public Health Nutr 2017;20:1054-62.

14. Du Toit G, Foong RM, Lack G. Prevention of food allergy Early dietary interventions. Allergol Int 2016;65:370-7.

15. Boudet-Berquier J, Salanave B, de Launay C, Castetbon K. Introduction of complementary foods with respect to French guidelines: description and associated socio-economic factors in a nationwide birth cohort (Epifane survey). Matern Child Nutr 2017;13:3.

16. Hollis JL, Crozier SR, Inskip HM, et al. Southampton Women's Survey Study Group. Age at introduction of solid foods and feeding difficulties in childhood: findings from the Southampton Women's Survey. Br J Nutr 2016;116:743-50.

17. McKinney CO, Hahn-Holbrook J, Chase-Lansdale PL, et al.; Community Child Health Research Network. Racial and ethnic differences in breastfeeding. Pediatrics 2016;138:2.

18. Fiocchi A, Dahdah L, Bahna SL, et al. Doctor, when should I feed solid foods to my infant? Curr Opin Allergy Clin Immunol 2016;16:404-11.

19. Fewtrell MS. Can optimal complementary feeding improve later health and development? Nestle Nutr Inst Workshop Ser 2016;85:113-23.

20. Marks K. Infant and toddler nutrition. Aust Fam Physician 2015;44:886-9.

21. Caramia G. Polyunsaturated fatty acids: omega-3 in child development Pediatr Med Chir 2002;24:337-45.

22. Greco L, Musmarra F, Franzese C, Auricchio S. Early childhood feeding practices in southern Italy: is the Mediterranean diet becoming obsolete? Study of 450 children aged 6-32 months in Campania, Italy. Cultural Paediatric Association. Acta Paediatr 1998;87:250-6.

23. Savino F, Zannino L, Laccisaglia A, Maccario S, Cresi F, Silvestro L, Mussa GC. Infant nutritional recommendations from pediatricians. Epidemiologic survey of feeding recommendations for the first year of life in Piedmont. Minerva Pediatr 2004;56:73-82.

24. van der Horst K, Sleddens EFC. Parenting styles, feeding styles and food-related parenting practices in relation to toddlers' eating styles: A cluster-analytic approach. PLoS One 2017;12:e0178149.

25. Murray RD. Savoring sweet: sugars in infant and toddler feeding. Ann Nutr Metab 2017;70 Suppl 3:38-46.

26. American Dietetic Association; Dietitians of Canada. Position of the American Dietetic Association and Dietitians of Canada: vegetarian diets. Can J Diet Pract Res 2003;64:62-81.

27. Doub AE, Moding KJ, Stifter CA. Infant and maternal predictors of early life feeding decisions. The timing of solid food introduction. Appetite 2015 Sep;92:261-8. 